\title{
Health Status of Women and Children During the 1310-1312 AH. Based on Dr.Klounieh's Studies and Reports
}

\section{A R T I C L E I N F O}

\section{Article Type}

Historical Original Research

\section{Authors}

Karimian A.* MSc

\section{How to cite this article}

Karimian A. Health Status of Wo-

men and Children During the

1310-1312 AH. Based on Dr.Kl-

ounieh's Studies and Reports. Sa-

rem Journal of Reproductive Me-

dicine. $2018 ; 2(2): 65-72$.
*Governmental Management Training Center, Tehran, Iran

\section{Correspondence}

Address: Sarem Women's Hospital, Basij Square, Phase 3, Ekbatan Town, Tehran, Iran. Postal Code: 1396956111

Phone: +98 (21) 44670888

Fax: +98 (21) 44670432

ali_karymiyan_2011@yahoo.com

\section{Article History}

Received: January 21, 2017

Accepted:May19,2017

ePublished: June 15, 2018

\section{A B S T RA C T}

Introduction In the Naser al-Din Shah era, some hospitals were established by a foreign advisor and Iranian physicians; but, they were not enough for the public needs with the high number of patients, especially in the case of common communicable diseases. First as an advisor and then as the head of the national health office of Iran, Dr. Klounieh was appointed to provide a comprehensive practical plan for health reform in Iran during three years. He developed a comprehensive report in 14 sections; in this article, we only presented some reports on the field of sexually transmitted diseases as well as women and children diseases.

Conclusion The reports prepared by the agents in each field can always be considered as valuable sources in scientific and historical studies and can giude researchers. Doctor-General Klounieh's report (Head of national health office of Iran) is one of the best examples. He prepared the comprehensive health status report for Iran in 1932-1934.

Keywords Dr.Klounieh; Health; Women; Children; National Health Office of Iran 


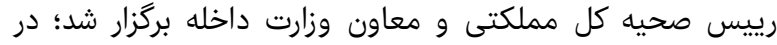

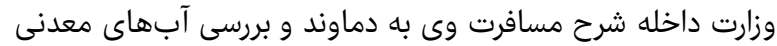

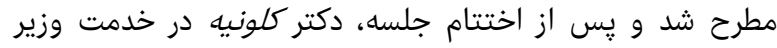

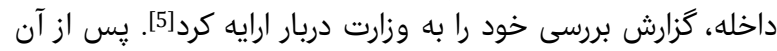
در راس تشكيلات صحيه، كلونيه فعاليت خود را را آغاز كرد.

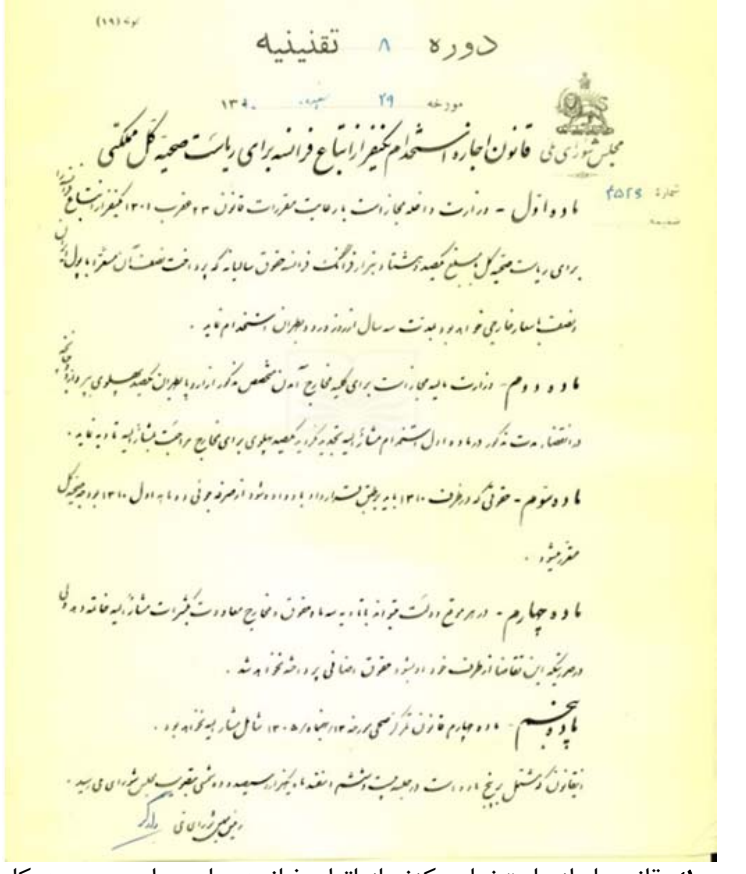

تصوير () قانون اجازه استخدام يكنفر از اتباع فرانسه براى رياست صحيه كل

جانمايه اين مقاله كزارش دكتر كلونيه در سالهاى •اسا تا عاسرا

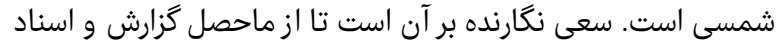

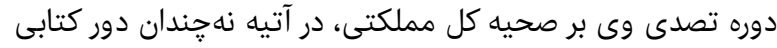

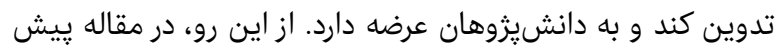

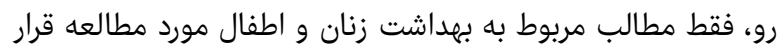

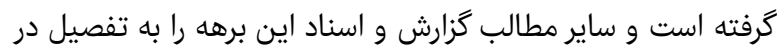

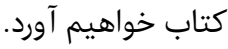

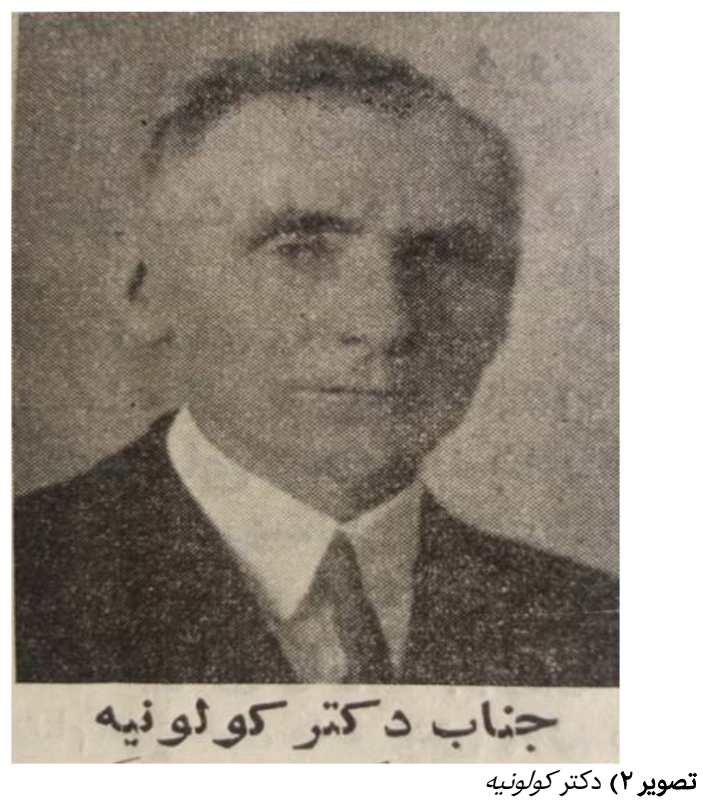

وضعيت سلامت بانوان و اطفال براساس مطالعات

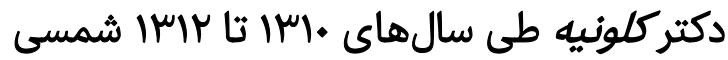

MSc "على كريميان

مركز آموزش مديريت دولتى، تهران، ايران

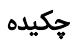

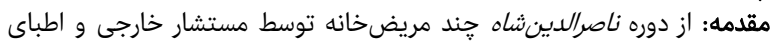

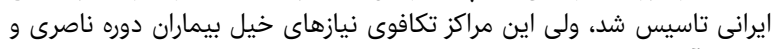

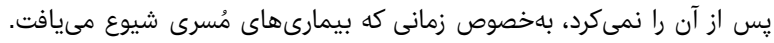

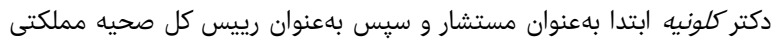

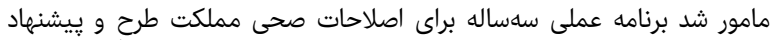

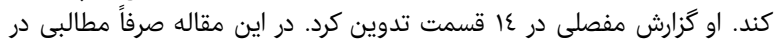

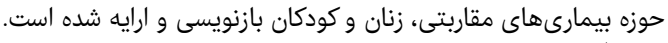

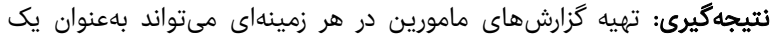

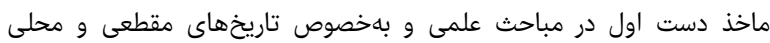

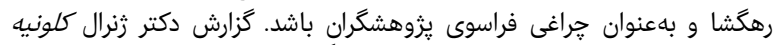

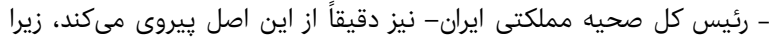

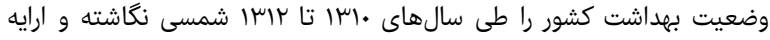

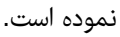
كليدوارهها: دكتر كلونيه، بهداشت، زنان، اطفال، اداره صحيه كل مملكتى ايران

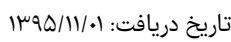

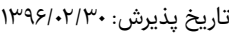

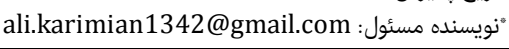

\section{مقدمه - مقاس}

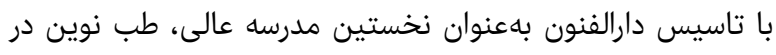

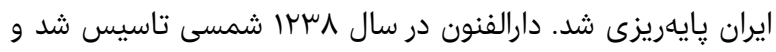

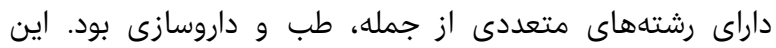

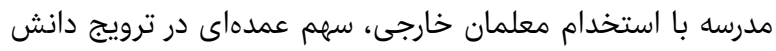

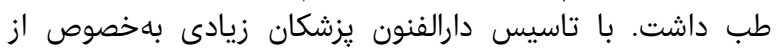

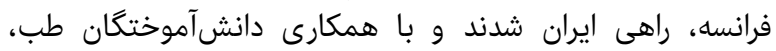

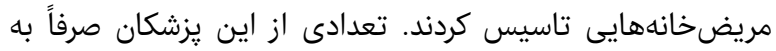

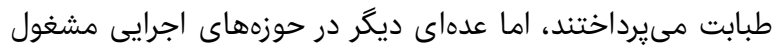

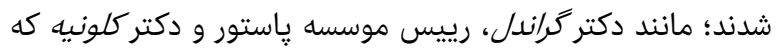

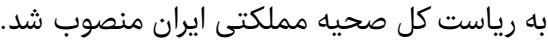

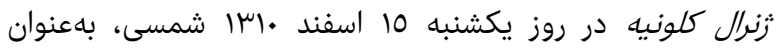

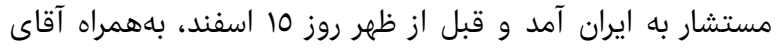

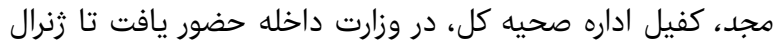

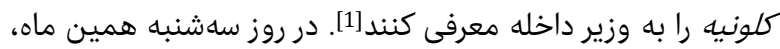

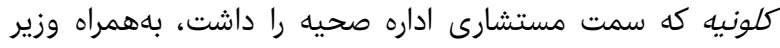

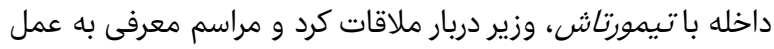

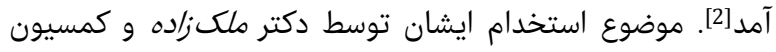

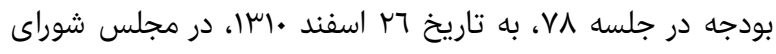

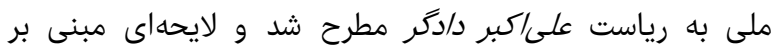

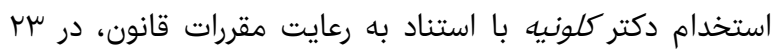

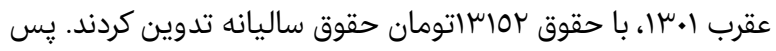

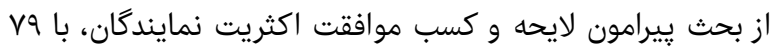

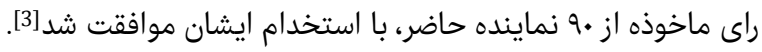

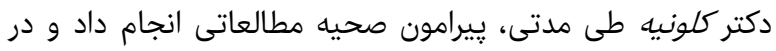

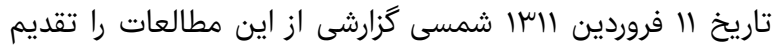

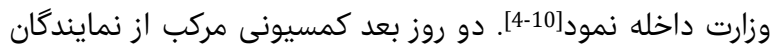

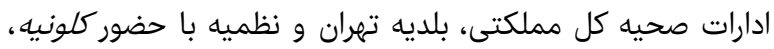




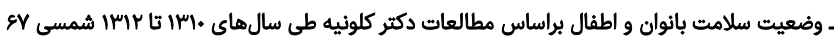

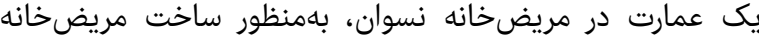

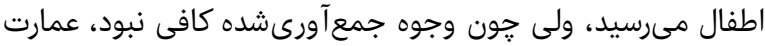

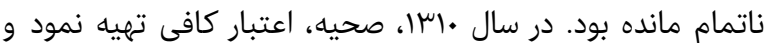
شروع به تكميل ساختمان مزبور كرد.

متصديان صحيه استانها و شهرستانها در سال ||س| شمسى اطباى صحى اطراف تهران

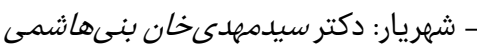

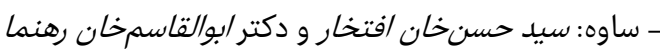

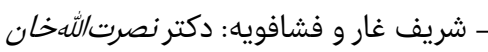

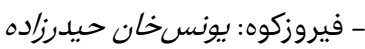

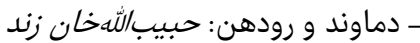

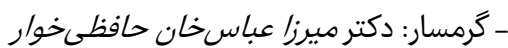

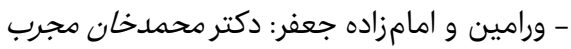

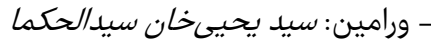

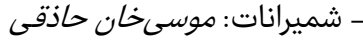

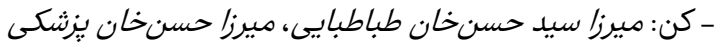

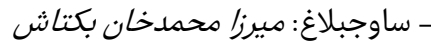

آذربايجان

- تبريز: دكتر سيد محمدخان موسوى، كفيل صحيه

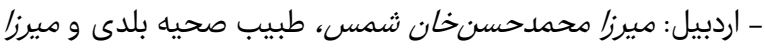

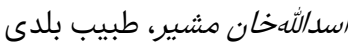

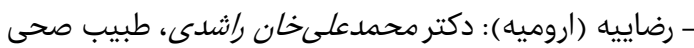

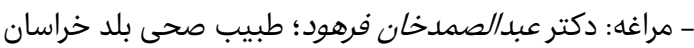

خراسان مران : - مثرن

- مشهد: دكتر حسن مخان افتخارى، طبيب صحى بلدى؛ دكتر

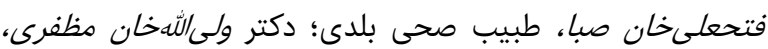

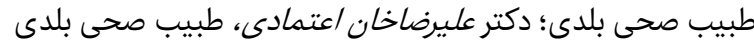

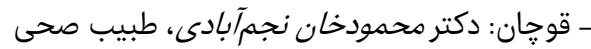

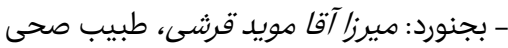

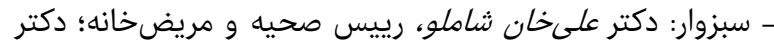

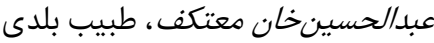

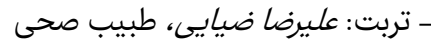

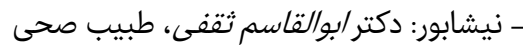

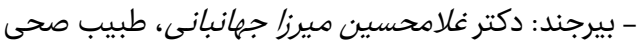

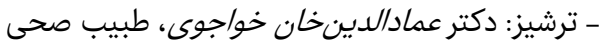

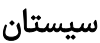

- زاهدان: دكتر مرتضىخان فريس، طبيب صحى

كرمان

- كرمان: دكتر مهدىخان فيلسوفزاده، رييس صحيه، دكتر

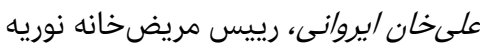
- رفسنجان: ميرزا /بوالقاسمخان ريدريمى مرئ، طبيب صحى بلدى نوريه

فارس

- شيراز: دكتر /بوالقاسمخان بهرامى، رييس اداره صحيه فارس و

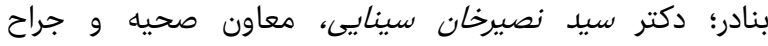

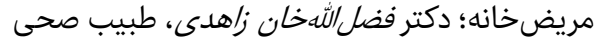

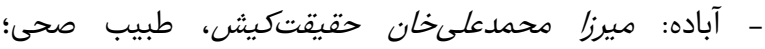

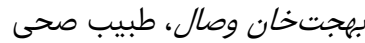

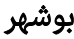

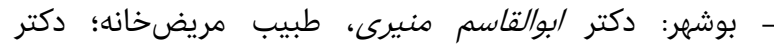

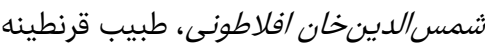

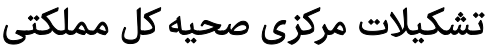

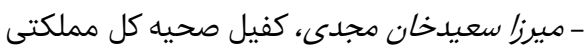

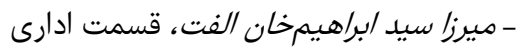

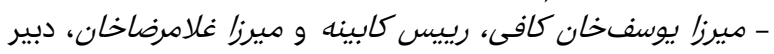
عضو سرويس محاسبات - ميرزا مصطفى سرويسن محاسبات ناصر، رييس محاسبات و آقاى ميززا جو/دخان

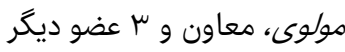

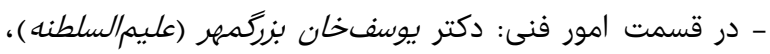

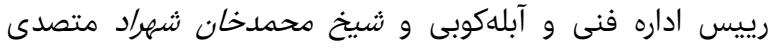

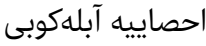

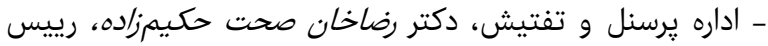

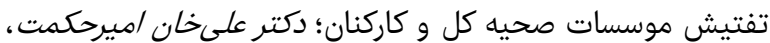

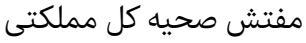

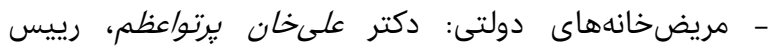

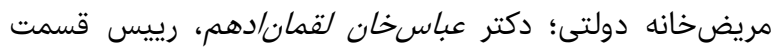

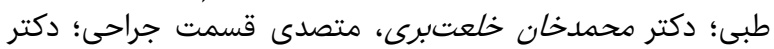

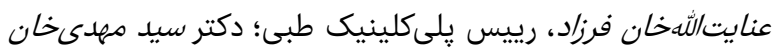

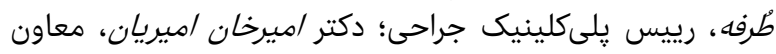

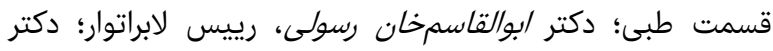

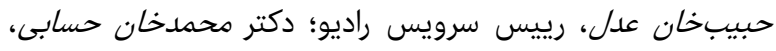

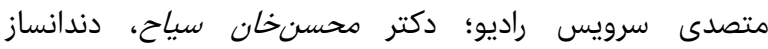

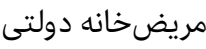

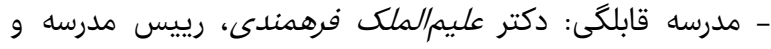

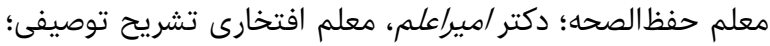

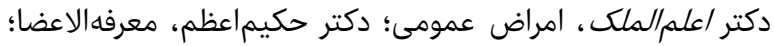

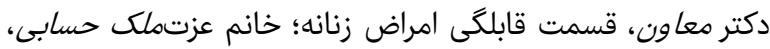

ناظمه

- مريض خاظهه وزيرى: دكتر مهدىخان ملكزاده، رييس مريض دخانه

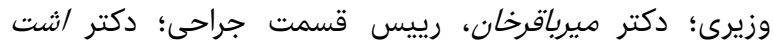

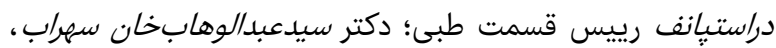

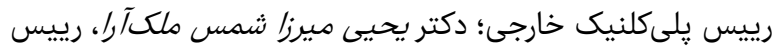

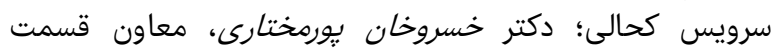

جراحى سرويس - مريضخانه نسوان: دكتر حسينخان، معاون طب داخلى؛

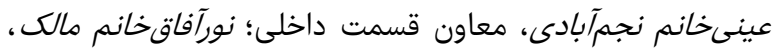

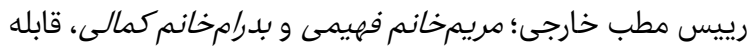

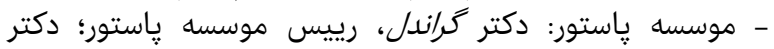

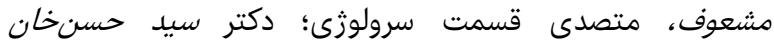

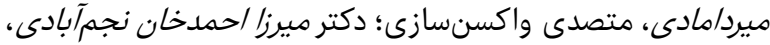

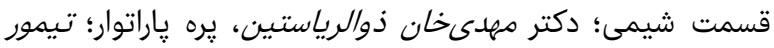

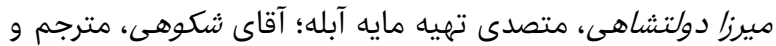

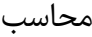

\section{مريض خانهها در حدود سال |سابل}

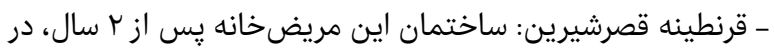

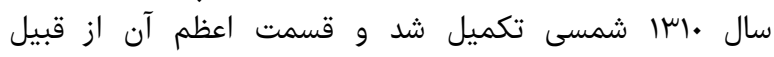

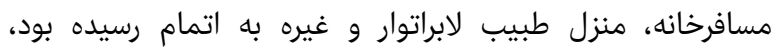

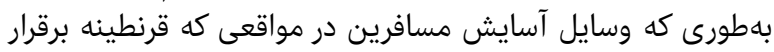

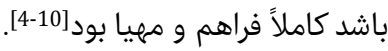

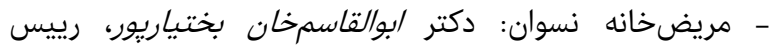

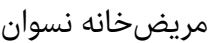

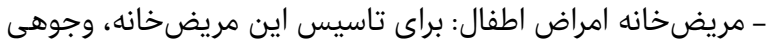

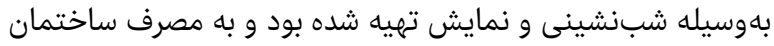




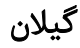

- رشت: دكتر علىخان شفان طبيب صحى؛ دكتر حسين خان مقدم،

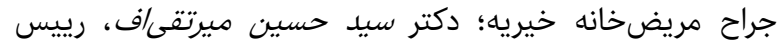

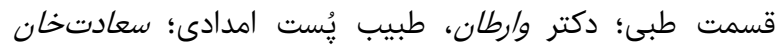

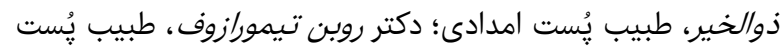

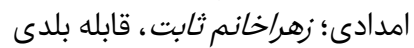

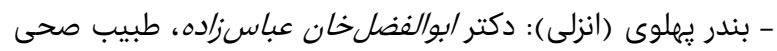

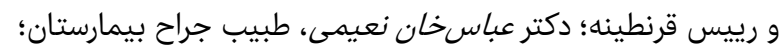

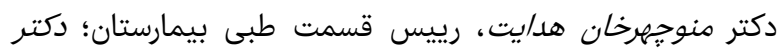

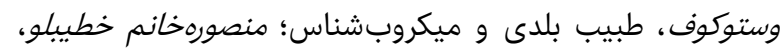

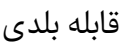
- لاهيجان: دكتر /حمدخان سياسى، طبيب صحىى؛ دكتر عليرض إناخان

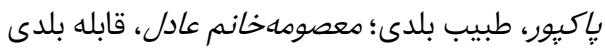

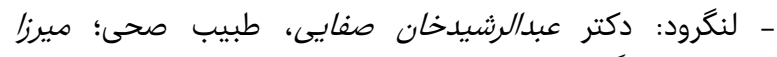

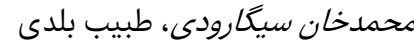

مازندران

- سارى: دكتر آرام خاجاطوريانس، طبيب صحى؛ ميرزا عبدالههخان

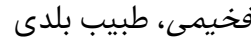
- بابل: دكتر حسين، طبين بلدين احسان، طبيب و جراح مريض خانه؛ دكتر

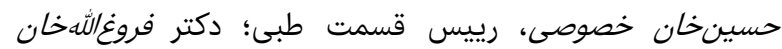

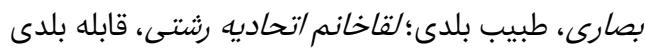

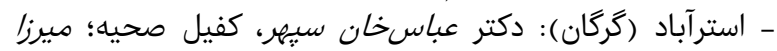

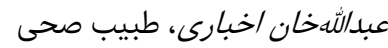
سمنان

- سمنان: ميرزا علىخان منتخب/لاطبا، طبيب صحى بلديه

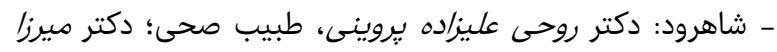

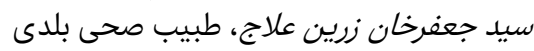
- دامغان: دكتر سيد حسين زين علاج، طبيب طيار طبيب طيار، طبيب صحى صلي

\section{خلاصهاى از رايورت صحيه كل مملكتى}

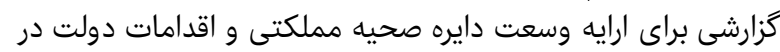

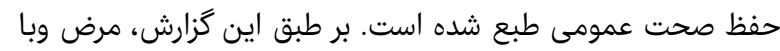

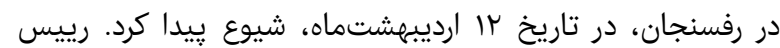

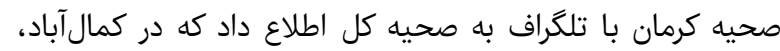

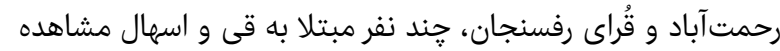

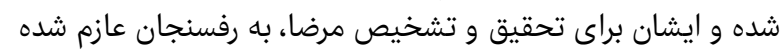

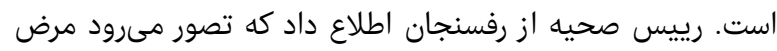

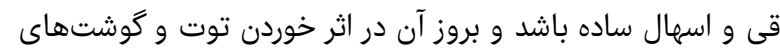

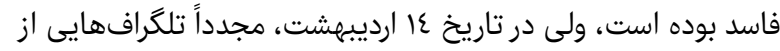

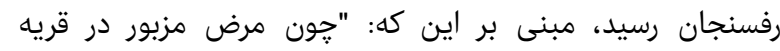

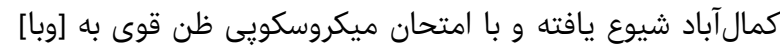

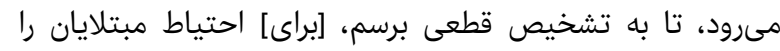

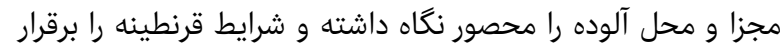
نمودند" [6]. شوراى صحى نظر به لزوم اقدامات فورى، جدى، تحقيق كامل در

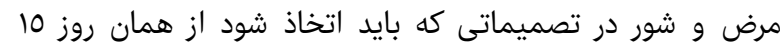

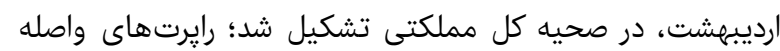

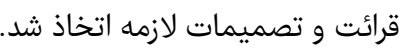

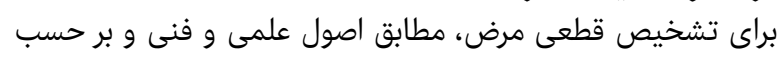

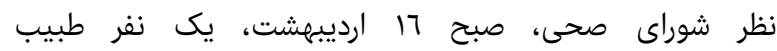
ميكروبشناس (دكتر مشعوف) از موسسه يُاستور عازم رفسنجان

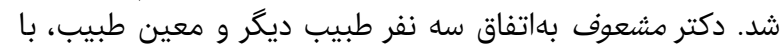

- بندرعباس: دكتر على علىخان عميديدى، طبيب صحى و قرنطينه

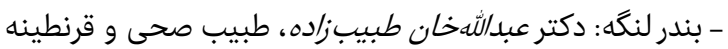

خوزستان - ناصرى (اهواز): دكتر سهرابخان برخورد/ر، رييس مريض خانهانه

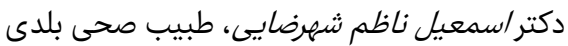

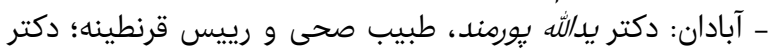

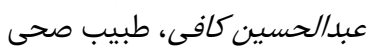

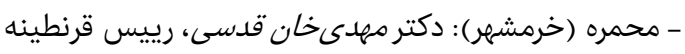

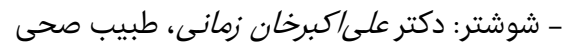

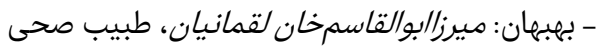

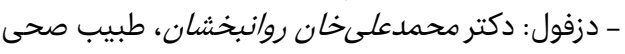

همدان - همدان: دكتر مهدىخان بديع، رييس صحيه؛ دكتر /بوالقاسم

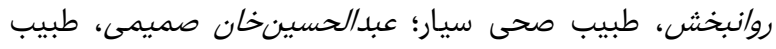

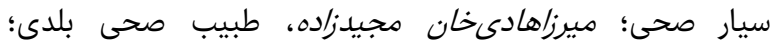
دوراخانم شيرازى، قابله مريضئ ميرهارئ ولايت ثلاث

- ملاير: دكتر عطالالهخان طبيبزاده، طبيب صحى و رييس مريض خانه ملاير

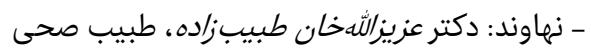

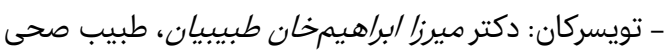

كرمانشاه

- كرمانشاه: دكتر عبداله ميرزا جمشيدى جهانسوزي، ريديس صحيس صحيه؛

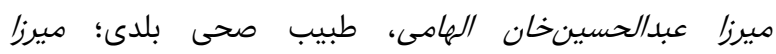

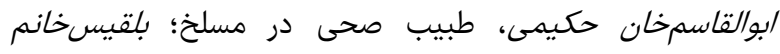
كوهرى، قابله لرستان

- خرم آباد: دكتر عباسخان حقيقت خواجوى، طبيب صحى

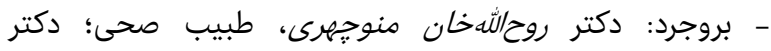

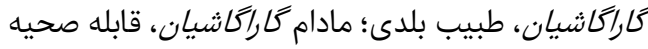

كردستان

- سنندج: دكتر باقرخان هنرمند، رييس صحيه؛ آقاى دانيالخان

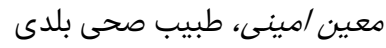

اصفهان

- اصفهان: دكتر سيد عبدالعلىخان طبيبى، رييس صحيه و مريض خانه شفايى - يزد: دكتر محمدخان طاهرى، رييس صحانه صحيه؛ ميرزا مسيح

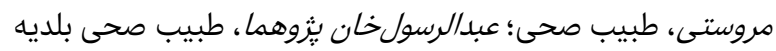

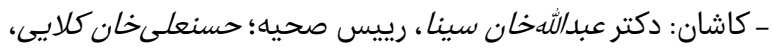
طبيب صحى بلديه - قم: دكتر سيد محمودخان مدرس بلديه زاده، طبيب صحى؛ ميرزا آقاخان

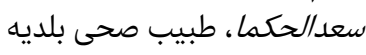

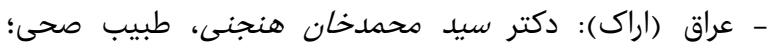

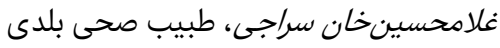

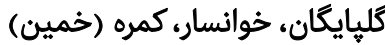

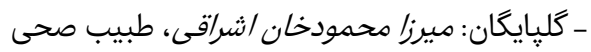

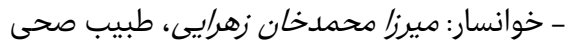

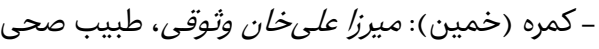

خمسه

- خمسه (زنجان): دكتر نادر ميرزاى نادرشاهى، طبيب صحى؛ دكتر

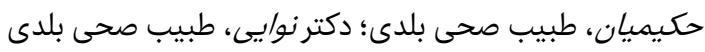

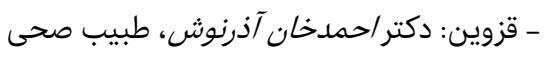


تشكيلات اداره صحيه كل مملكتى در دوره رياست دكتر

كلونيه

از سال السا تشكيلات اداره صحيه كل از قرار: دكتر زنرال كولونيه،

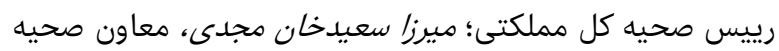

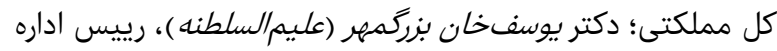

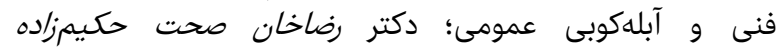

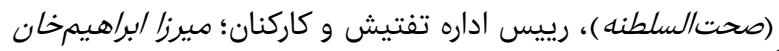

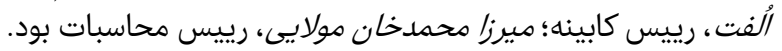
امور صحى سرحدات براساس گزارشهاى موحرات موجود، قرنطينههاى بنادر خليج فارس در

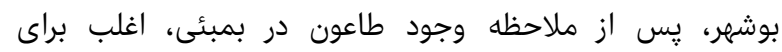

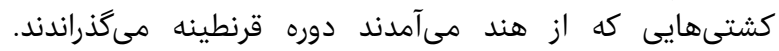

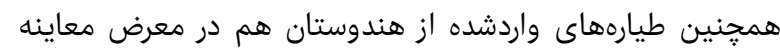

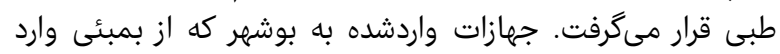

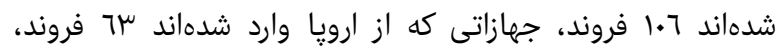

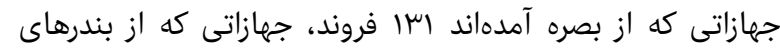

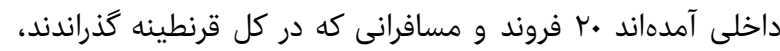

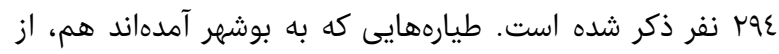

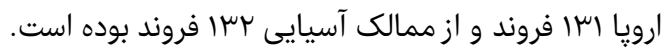

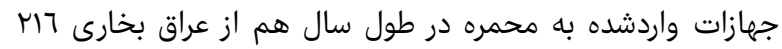

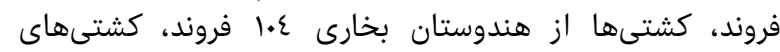

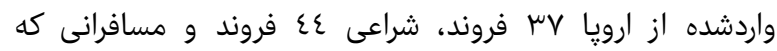

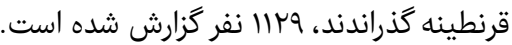

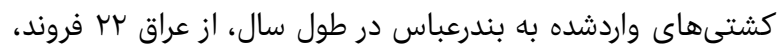

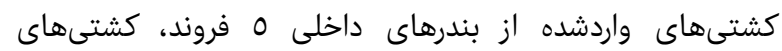

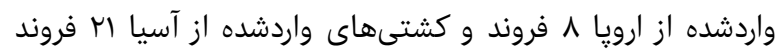
بوده است.

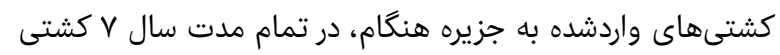

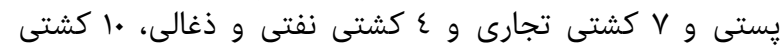

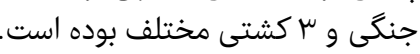
قرنطينههاى بحرى سواحل بحر خزر

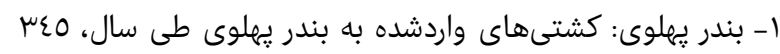

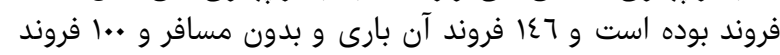

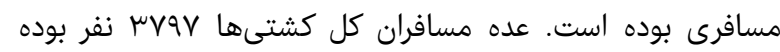

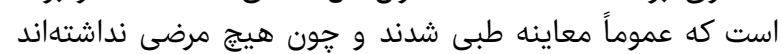

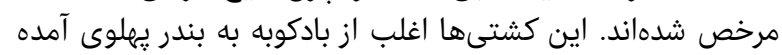

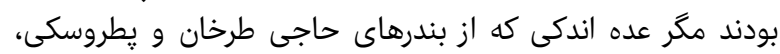
مستقيم از روسيه آمده بودند.

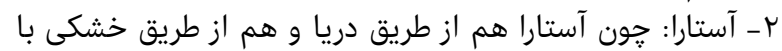

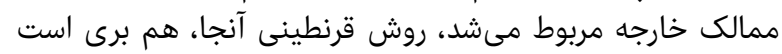

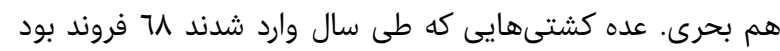

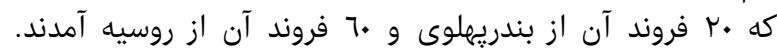

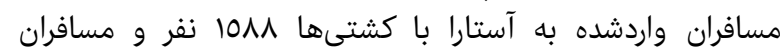

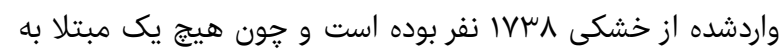

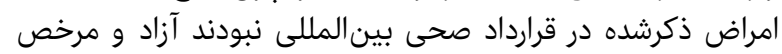

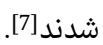

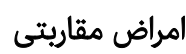
در روزنامه شفق درارئى رابطه با امراض مقاربتى به سال rاسا آمده

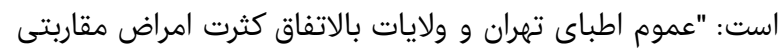

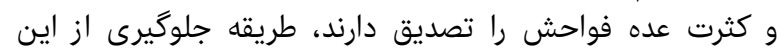

لوازم كار و مقدارى واكسن و دواجات و ادويه ضدعفونى، بهوسيله

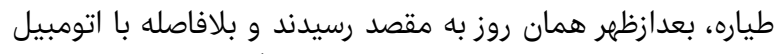

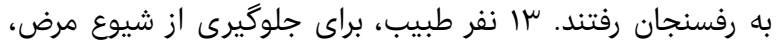

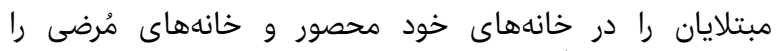

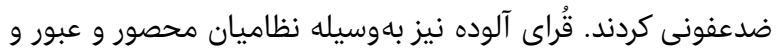

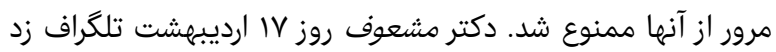

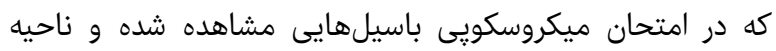

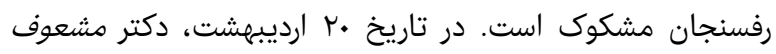

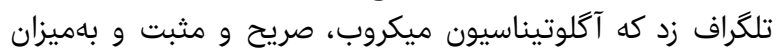

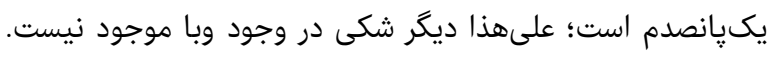

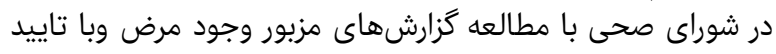

شد.

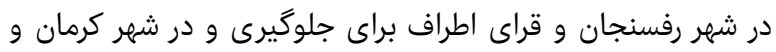

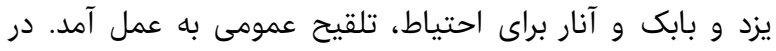

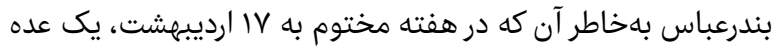

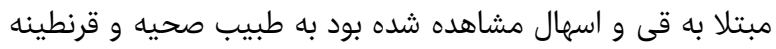

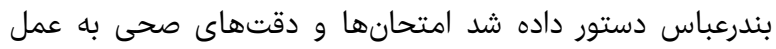

آورند.

جون در تاريخ 19 ارديبهشت، وجود مرض وبا بهوسيله امتحانهاى

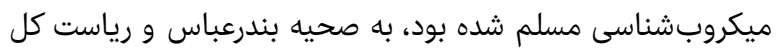

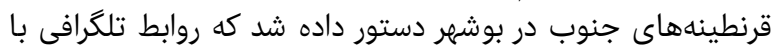

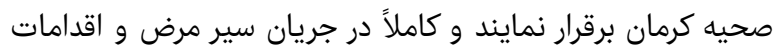

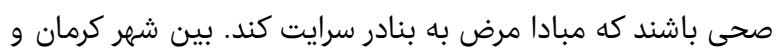

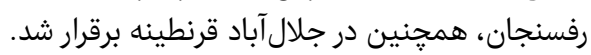

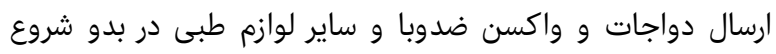

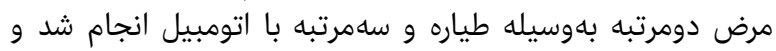

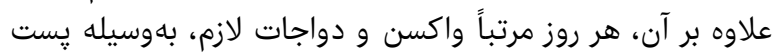

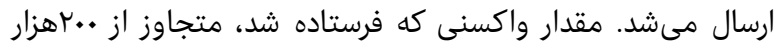

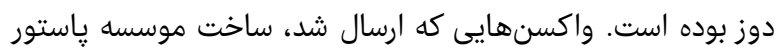

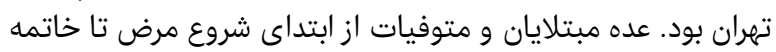

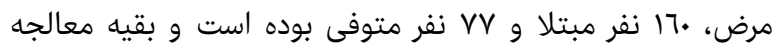

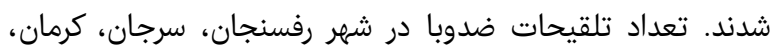

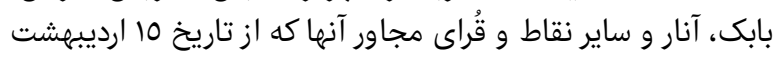

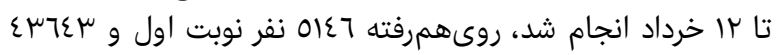
نفر در نوبت دوم بوده است.

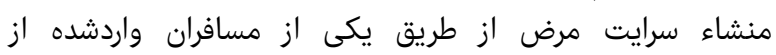

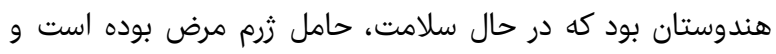

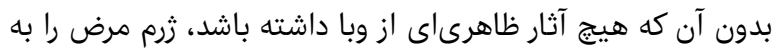

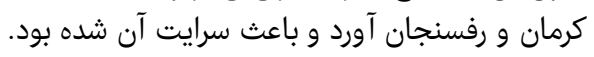

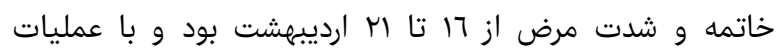

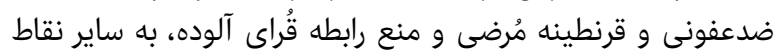

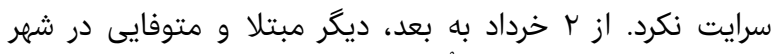

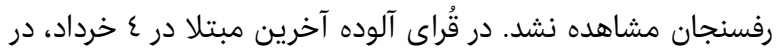

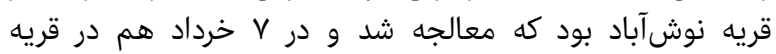

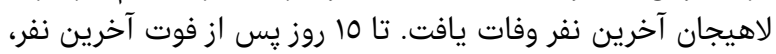

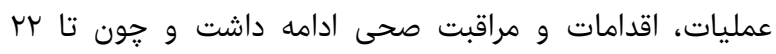

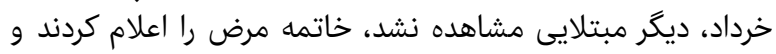
اقدامات صحى موقوف شد. اطباى اعزامى بهتدريج مردئ مراجعت كردند مرند

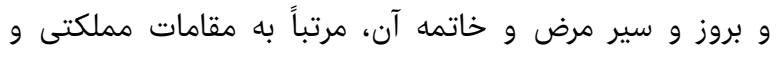

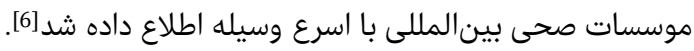


به خدمت به ترتيب ذيل از ماخذ فلان رتبه مستخدمى رسمى (كه

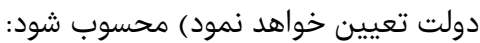

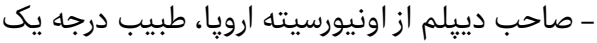

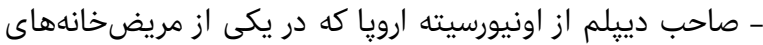

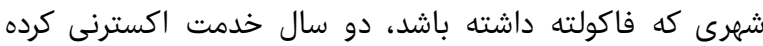
باشد، طبيب درجه دوم فولنه

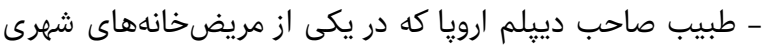

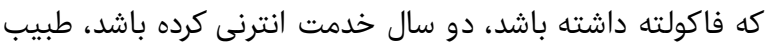
درجه سوم

- طبيب صاحب دييلم ارويا كه در يكى از مريض دانهانهاى شهاى شهرى

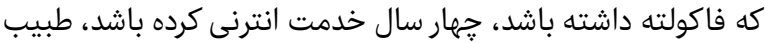
درجه جهارم - طبيب صاحب دييلم كه حايز مقام يروفسور اگرزه شده باشد، طبيب درجه ششم كاحب دئ

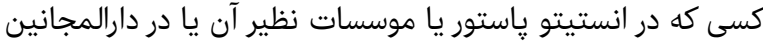

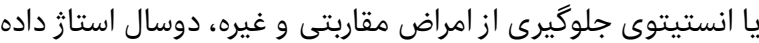

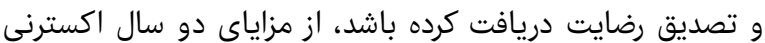

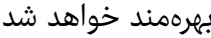

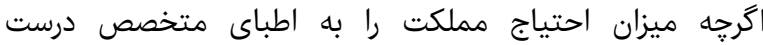
نمىدانم، ولى معتقدم كه براى اطباى ذيل ديل درجات آتى راجى را بايد

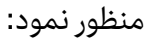

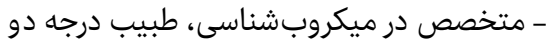

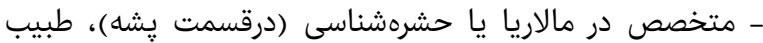
درجه دو

- متخصص در معالجه مجانين، طبيب درجه سوم رجمي

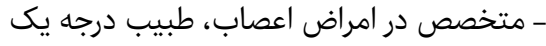

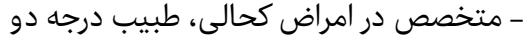

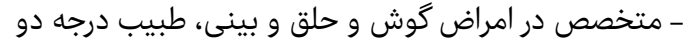

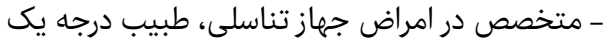

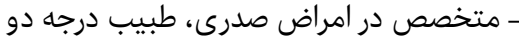

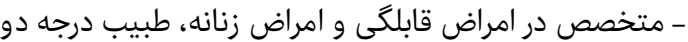

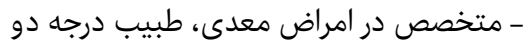

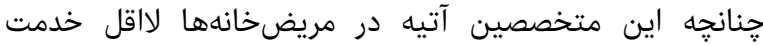

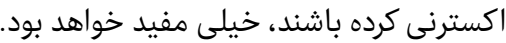

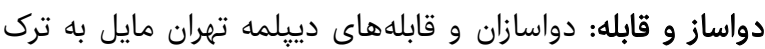

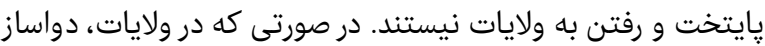

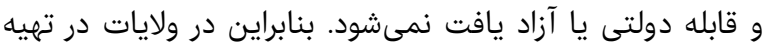

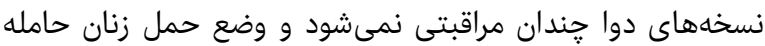

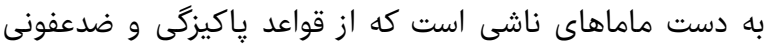

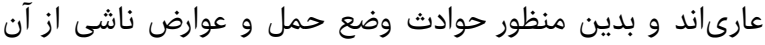

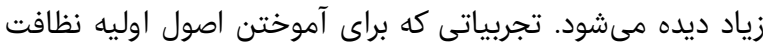

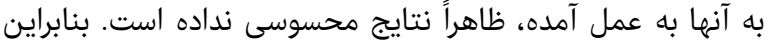

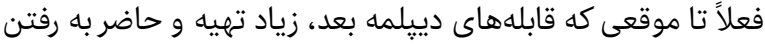

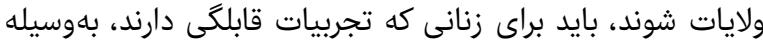

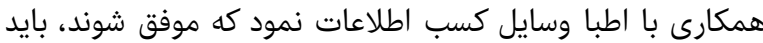

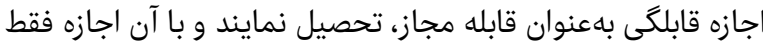

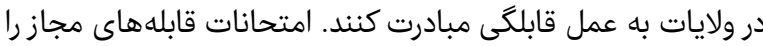

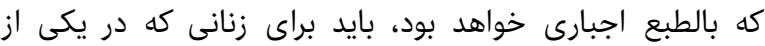

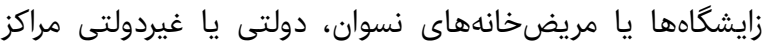

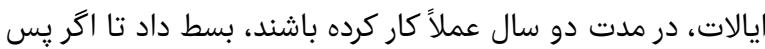

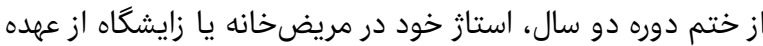
امتحان برآيند، جواز به آنها داده شوان شود دود درد

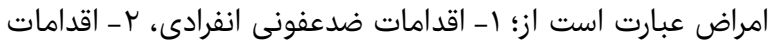

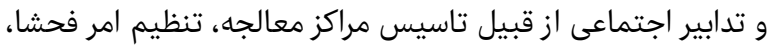

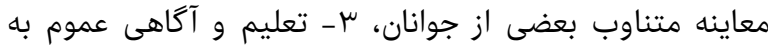

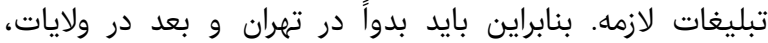

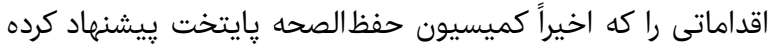

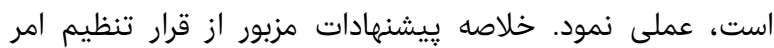

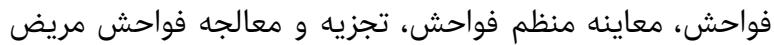

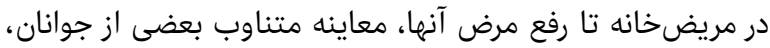

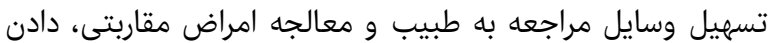
نصايح و دستورهاى حفظ الصحه به مردم است ف8

\section{دو سند از كتابخانه ملى ايران}

دست آخر به دو سند از اسناد موجود در كتابخانه ملى ايران ايران

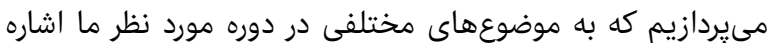

تلفات اطفال: ميزان نسبت تلفات اطفال را جز بهوسيله تهيه

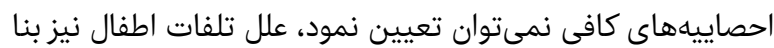

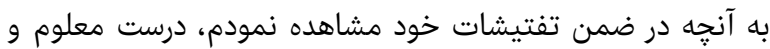

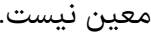

علىالتحقيق، علل تلفات اطفال در هر نقطه با نقطه ديگر اختلاف

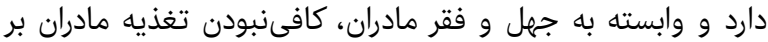

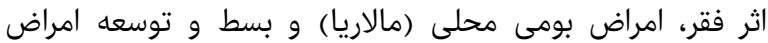

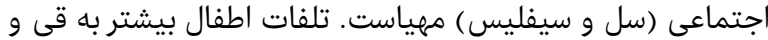

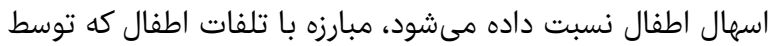

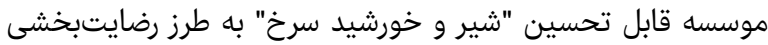

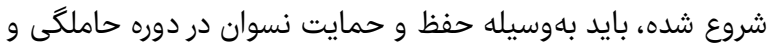

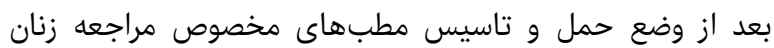

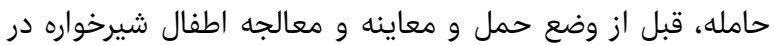
موسسات صحى عمومى دولتى يا غيردولتى توسعل موسعه يابد.

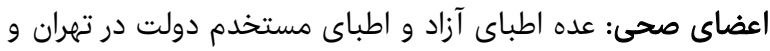

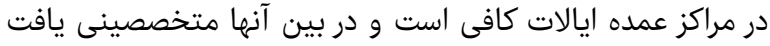

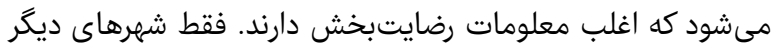

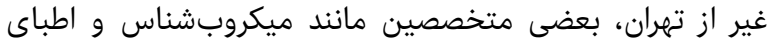

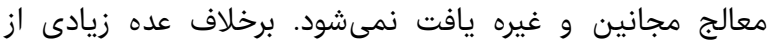

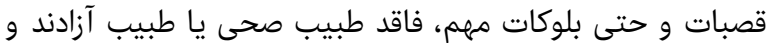

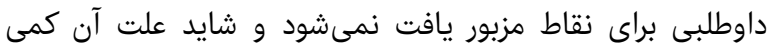

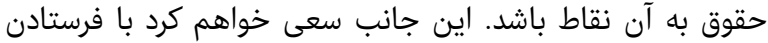

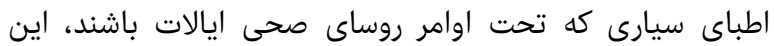

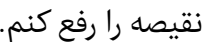

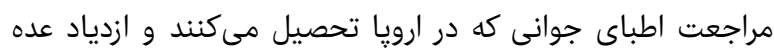

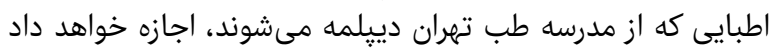

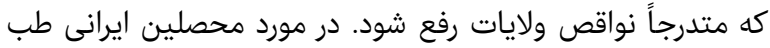

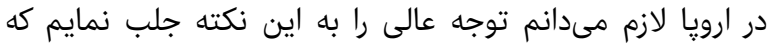

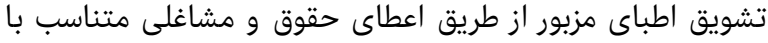

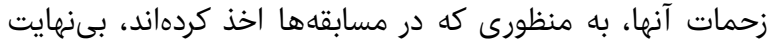

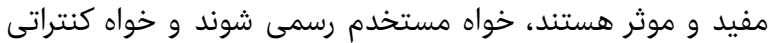

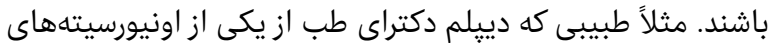

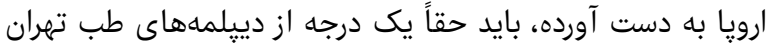

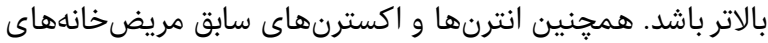

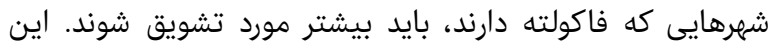

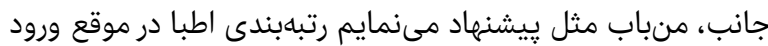




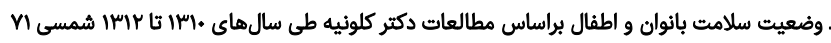

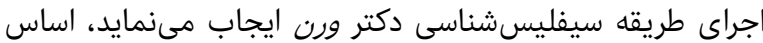

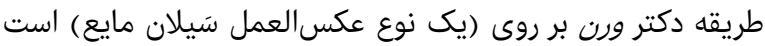

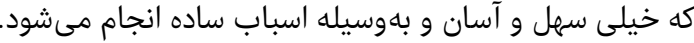

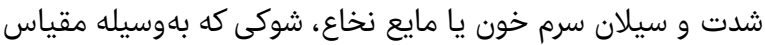

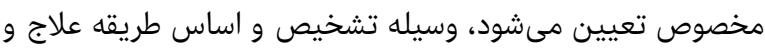

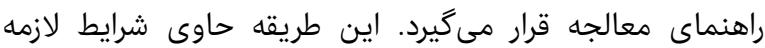

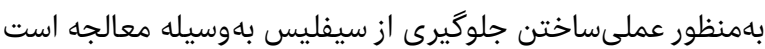

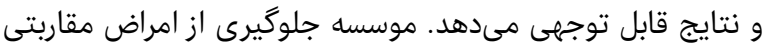

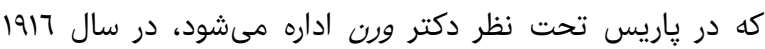

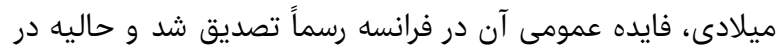

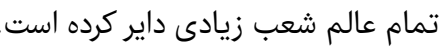

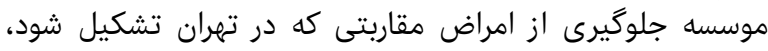

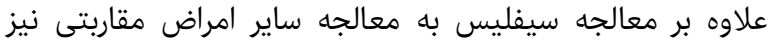

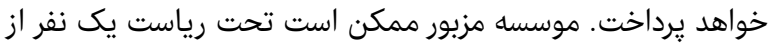

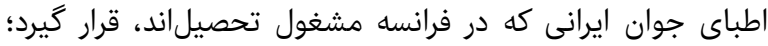

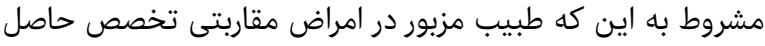

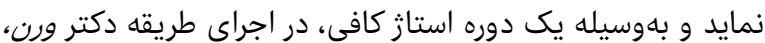

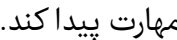

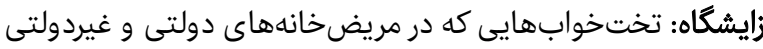

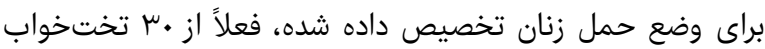

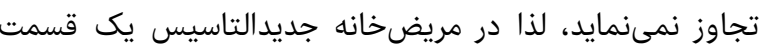

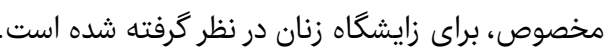

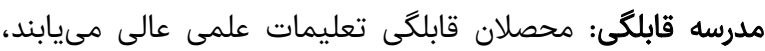

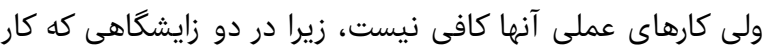

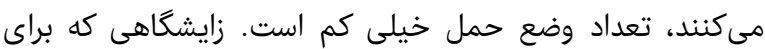

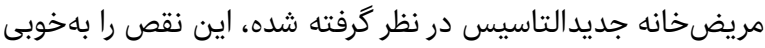

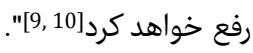

\section{نتيجه گیرى}

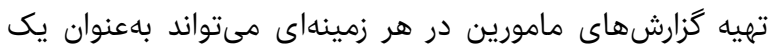

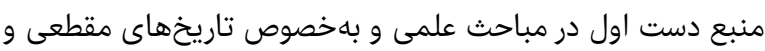

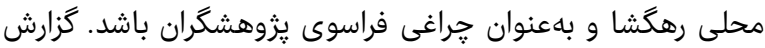

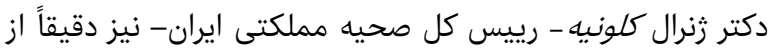

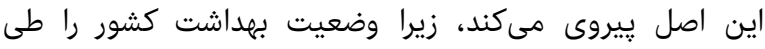

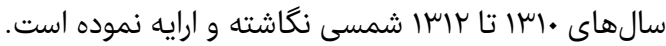

تشكر و قدردانى: موردى از سوى نويسنده گزارش نشده است.

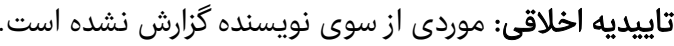

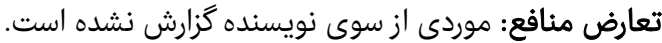

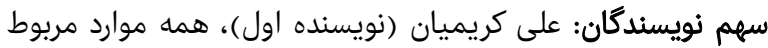

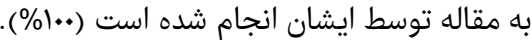
منابع مالى: موردى از سوى نويسنده گزارش نشام نشده است.

منابع

1- Safavi S. Kooshesh Newspaper. 1932 Mar 7; 10(1792). [Persian]

2- Safavi S. Kooshesh Newspaper. 1932 Mar 10; 10(1795). [Persian]

3- Safavi S. Kooshesh Newspaper. 1932 Mar 18; 10(1932).

[Persian]

4- Safavi S. Kooshesh Newspaper. 1932 Mar 31; 10(1808).

[Persian]

5- Safavi S. Kooshesh Newspaper. 1932 Apr 1; 10(1809).

[Persian]
اين قابلههاى مجاز فقط حق خواهند داشت در ايالتى كه دوره

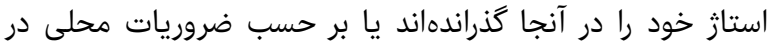

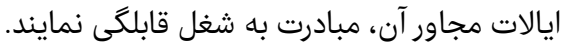

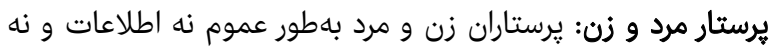

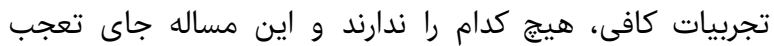

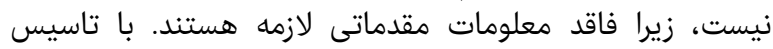

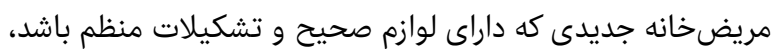

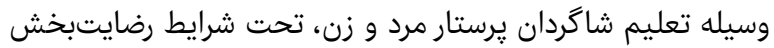
تهييه خواهد شد. توسيل تعليم شارك

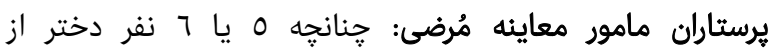

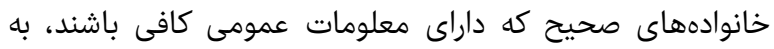

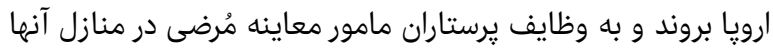

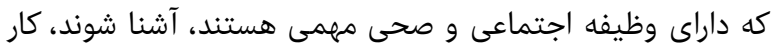

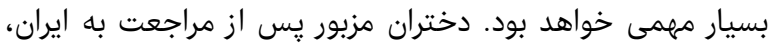
معلمه يرستاران ديكر خواهند شد بود.

\section{موسسات صحى، مريضخانههاى طهران}

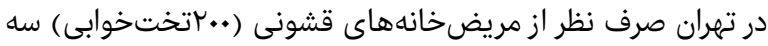

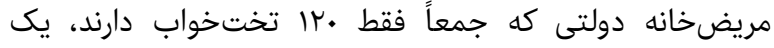

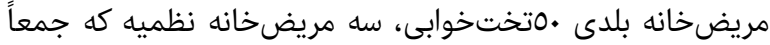

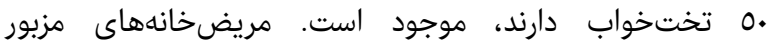

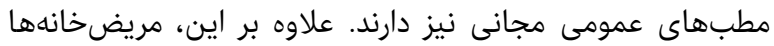

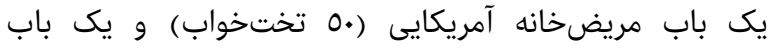

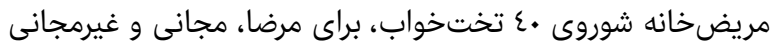

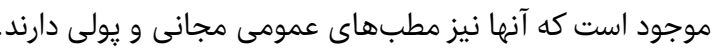

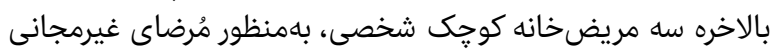

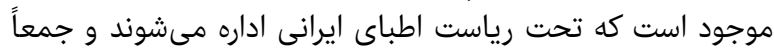

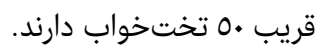

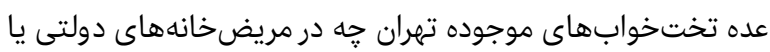

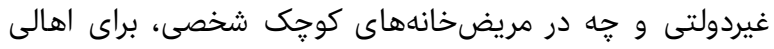

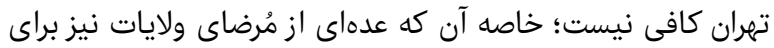

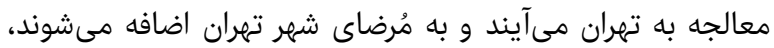

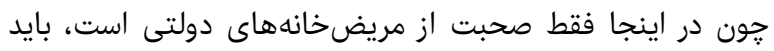

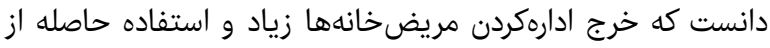

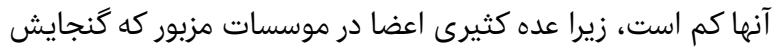

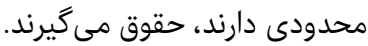

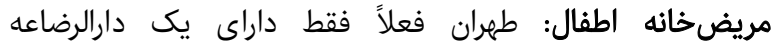

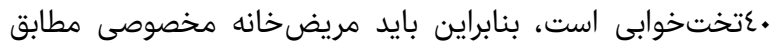

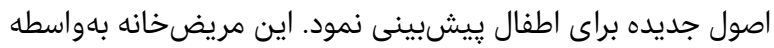

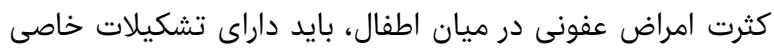

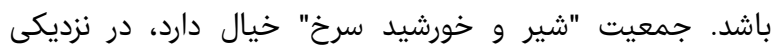

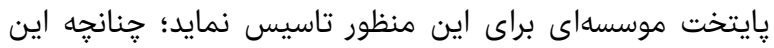

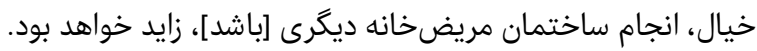

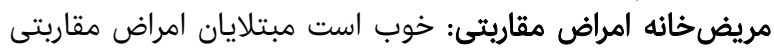

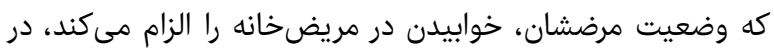

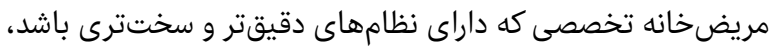
تحت معالجه و مداوا قرار گيرند.

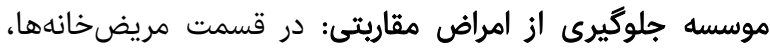

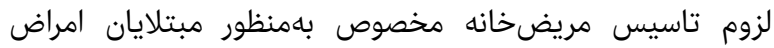

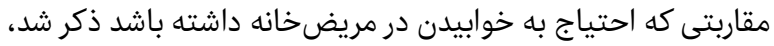

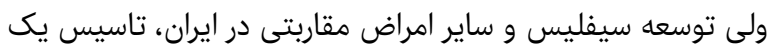

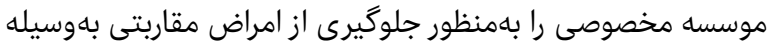


9- National Library and Archives of Iran. Accession No.1030046443. Tehran: National Library and Archives of Iran. [Persian]

10- National Library and Archives of Iran. Accession No.1030046349. Tehran: National Library and Archives of Iran. [Persian]
6- Jahed A. Pars Yearbook. ، Tehran: Unknown Publisher. 1932. p. 57-60. [Persian]

7- Jahed A. Pars Yearbook. ،Tehran: Unknown Publisher. 1932. p. 108-10. [Persian]

8- Anonymous Writrer. Shafagh Newspaper. 1933 Aug 27; 12(2435). p.2. [Persian] 